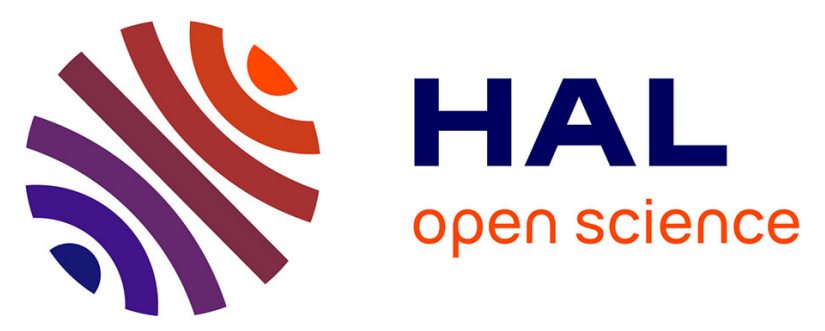

\title{
Supporting air traffic control collaboration with a tabletop system
}

\author{
Stéphane Conversy, Hélène Gaspard-Boulinc, Stéphane Chatty, Stéphane \\ Valès, Carole Dupré, Claire Ollagnon
}

\section{- To cite this version:}

Stéphane Conversy, Hélène Gaspard-Boulinc, Stéphane Chatty, Stéphane Valès, Carole Dupré, et al.. Supporting air traffic control collaboration with a tabletop system. CSCW 2011 ACM conference on Computer Supported Cooperative Work, Mar 2011, Hangzhou, China. pp 425-434, 10.1145/1958824.1958891 . hal-01022257

\section{HAL Id: hal-01022257 \\ https://hal-enac.archives-ouvertes.fr/hal-01022257}

Submitted on 22 Jul 2014

HAL is a multi-disciplinary open access archive for the deposit and dissemination of scientific research documents, whether they are published or not. The documents may come from teaching and research institutions in France or abroad, or from public or private research centers.
L'archive ouverte pluridisciplinaire HAL, est destinée au dépôt et à la diffusion de documents scientifiques de niveau recherche, publiés ou non, émanant des établissements d'enseignement et de recherche français ou étrangers, des laboratoires publics ou privés. 


\section{Supporting Air Traffic Control collaboration with a TableTop System}

\author{
Stéphane \\ Conversy ${ }^{1,2}$ \\ Hélène Gaspard- \\ Stéphane
${ }^{1}$ Université de Toulouse ${ }^{2}$ Université de Toulouse ENAC IRIT

\begin{abstract}
Collaboration is key to safety and efficiency in Air Traffic Control. Legacy paper-based systems enable seamless and non-verbal collaboration, but trends in new software and hardware for ATC tend to separate controllers more and more, which hinders collaboration. This paper presents a new interactive system designed to support collaboration in ATC. We ran a series of interviews and workshops to identify collaborative situations in ATC. From this analysis, we derived a set of requirements to support collaboration: support mutual awareness, communication and coordination, dynamic task allocation and simultaneous use with more than two people. We designed a set of new interactive tools to fulfill the requirements, by using a multi-user tabletop surface, appropriate feedthrough, and reified and partially-accomplishable actions. Preliminary evaluation shows that feedthrough is important, users benefit from a number of tools to communicate and coordinate their actions, and the tabletop is actually usable by three people both in tightly coupled tasks and parallel, individual activities. At a higher level, we also found that co-location is not enough to generate mutual awareness if users are not engaged in realistic tasks.
\end{abstract}

\section{Author Keywords}

CSCW, tabletop, system design, collaboration, Air Traffic Control

\section{ACM Classification Keywords}

H.5.3 Information Interfaces and Presentation: Group and Organization Interfaces;

\section{INTRODUCTION}

The goal of Air Traffic Control is to maximize two properties: safety (avoiding accidents) and capacity (raising the number of manageable flights). ATC is a highly collaborative activity [4]. Collaboration makes controllers more efficient and is essential for safety. The trustworthiness of the system comes not only from its individual parts (hardware, software, or people), but emerges from the process of checking and crosschecking the activity of teammates [1]. As with many other activities, various computer systems have been introduced to support ATC. However, most systems introduced have been largely based on single-person paradigms: hence, computerization

\author{
Stéphane \\ Valès ${ }^{3}$ \\ Carole \\ Dupré $^{3}$ \\ Claire \\ Ollagnon $^{4}$ \\ ${ }^{3}$ IntuiLab \\ ${ }^{4}$ Intactile Design
}

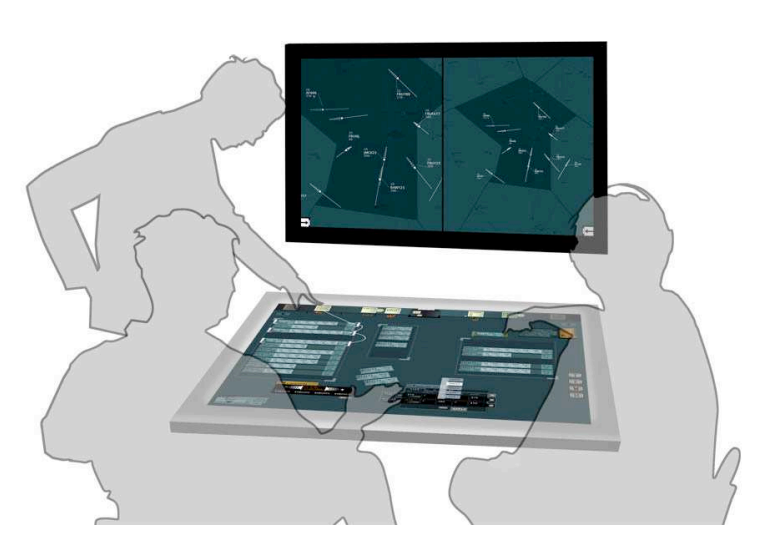

Figure 1: hardware and visualization settings

has been done at the expense of collaboration. Recent hardware advances in multi-touch multi-user tabletop systems enable us to imagine new potential solutions for collaboration support. We designed a set of new interactive tools relying on a multi-user tabletop surface, appropriate feedthrough, and reified and partially-accomplishable actions.

\section{SYSTEM REQUIREMENTS}

Based on an analysis of collaborative situations in ATC, we devised a set of requirements for our system. Our primary design goal was to foster seamless collaboration by requiring less explicit communication and fewer coordination acts. Our main assumption is that better collaboration will yield benefits in terms of capacity and safety. More precisely, the system should...

- ... enable users to inform the systems with their clearances, which is not possible with current, paperbased systems [3].

- ... allow more than two users to interact simultaneously with it. This should allow capacity increases since multiple users will be able to handle tasks concurrently (parallelization)

- ... foster mutual awareness. Safety should increase because users will have more means to be aware of teammates' activity and more means to detect problems (more eyeballs). 
- ... foster communication and coordination. This should improve both safety (knowledge of teammate actions) and capacity (less latency).

- ... foster dynamic task allocation. Capacity should increase because users will be able to pick up new tasks to be done as soon as they have completed existing tasks (workload balancing).

\section{SYSTEM DESIGN}

The requirements can be fulfilled if users are aware of tasks to be done, or are able to evaluate workload of their colleague. In addition, it can only be done if any user is allowed to interact with any representation or tools while the other user is engaged in another task. We used a shared, multi-touch, multi-users surface as the basis of our system. Shared surface are supposed to exhibit these properties: users are close to each other, and they enable interacting simultaneously if designed appropriately. We devised the following guidelines to design interactive tools so that they support collaboration:

- Reify actions into objects. Since objects lie on the table, their manipulation may enable accountability [1]; furthermore, they can be passed around and allow for task reallocation.

- Enable partial accomplishment of actions. An action can be separately prepared, checked and accomplished, possibly by different users, thus offering seamless workload allocation.

- Provide as much as feedback as possible. Since activities must be accountable, it is important that appropriate feedback provide an opportunity for teammates to observe one another's actions.

We also used several guidelines from tabletop and CSCW literature (orientation [2], territoriality [5], tabletop [1], direct collaboration [1] and coupling [1]). In the following, we mention the guidelines that we applied. We chose not to prevent inter-controller conflicts using technical features; instead, we relied on social norms. We designed several software tools, such as layout-free, orientable strips, editors, Post-it, an extrapolation tool, a timeline, several feedthrough, delayed audio annotation etc.

\section{PRELIMINARY EVALUATION}

We have conducted four experiments to evaluate our design choices. The experiments were qualitative and involved a limited number of subjects and trials. As such, they yielded preliminary results only; however, we did make several useful observations. The experiments were not meant to test whether our system is better than current systems in terms of capacity or safety. Rather, they test to what extent the first three requirements we listed above (more than two users, mutual awareness, communication, coordination, dynamic task allocation) are fulfilled. Preliminary evaluation shows that feedthrough is important, users benefit from a number of tools to communicate and coordinate their actions, and the tabletop is actually usable by three people both in tightly coupled tasks and parallel, individual activities. At a higher level, we also found that co-location is not enough to generate mutual awareness if users are not engaged in realistic tasks.

\section{ACKNOWLEDGMENT}

The project was funded by Eurocontrol Experimental Center under grant EEC A06/12013BE.

\section{REFERENCES}

1. Hughes, J. A., Randall, D., and Shapiro, D. 1992. Faltering from ethnography to design. In Proc. of CSCW '92. ACM, New York, NY, 115-122.

2. Kruger, R., Carpendale, S., Scott, S. D., and Tang, A. 2005. Fluid integration of rotation and translation. In Proc. of CHI '05. ACM Press, 601-610.

3. MacKay, W. E. 1999. Is paper safer? The role of paper flight strips in air traffic control. ACM Trans. Comput.Hum. Interact. 6, 4 (Dec. 1999), 311-340.

4. Rognin, L., Salembier, P., Zouinar, M. 2000. Cooperation, reliability of socio-technical systems and allocation of function. In Int. J. Human-Computer Studies, (2000) 52, 357-379.

5. Scott, S.D., Grant, K.D., and Mandryk, R.L. System guidelines for co-located, collaborative work on a tabletop display. In Proc. of ECSCW 2003, Springer (2004), p159-178.

6. Scott, S. D., Sheelagh, M., Carpendale, T., and Inkpen, K. M. 2004. Territoriality in collaborative tabletop workspaces. In Proc. of CSCW'04. ACM Press, 294303.

7. Sire, S., Chatty, S., Gaspard-Boulinc, H., Colin, F.-R. 1999. How can groupware preserve our coordination skills? Designing for direct collaboration. In Proc. of Interact 99, IFIP, pp. 304-312.

8. Tang, A., Tory, M., Po, B., Neumann, P., and Carpendale, S. 2006. Collaborative coupling over tabletop displays. In Proc of CHI'06. ACM Press, 11811190. 